\title{
NON-DESTRUCTIVE ASSESSMENT OF GLUING IN CROSS-LAMINATED TIMBER PANELS
}

\author{
GIOVANNA CONCU ${ }^{1}$, MASSIMO FRAGIACOMO ${ }^{2}$, NICOLETTA TRULLI $^{1} \&$ MONICA VALDÈS $^{1}$ \\ ${ }^{1}$ Department of Civil and Environmental Engineering and Architecture, University of Cagliari, Italy \\ ${ }^{2}$ Department of Civil, Construction-Architectural \& Environmental Engineering, University of L'Aquila, Italy
}

\begin{abstract}
Cross Laminated Timber (CLT) panels are wooden structural products consisting of finger jointed boards glued together and arranged in orthogonal layers. The lamination process reduces the scatter of the board properties so that minor strength reducing features such as knots and other defects are dispersed in the product. CLT panels have very high axial load-carrying capacity and bending strength, due to their large resisting areas, and high shear strength. However, the structural performance of CLT panels depends on the proper application of the glue between the layers. The bond set up at the interface between longitudinal and orthogonal layers can be seriously compromised by the lack of gluing occurring during the production process. For this reason, quality control is an essential tool for verifying the correct gluing process of CLT panels. This paper illustrates the preliminary results of an experimental programme aimed to test the effectiveness of Ultrasonic Testing (UT) in detecting adhesion anomalies and defects in CLT panels. UT was carried out on several CLT panels having different configurations (length, thickness of the layers, number of layers, timber species). For each panel, the velocity of longitudinal stress wave $V$ was measured along several paths perpendicular to the plane of the CLT panels. $V$ data was numerically processed and then for each panel the distribution of $V$ on a horizontal plane was graphically represented implementing the iso-velocity curves. The match between the low-velocity areas resulting from data processing and the unglued areas visually assessed was evaluated and critically discussed.
\end{abstract}

Keywords: CLT, timber, gluing, NDT, Ultrasonic Testing.

\section{INTRODUCTION}

Cross Laminated Timber (CLT) panels are wooden structural products consisting of at least three layers of finger jointed boards glued together and arranged in orthogonal layers. International codes require that only wood previously graded according to the current regulations can be used as structural material [1].

CLT panels are used in construction due to their outstanding mechanical properties such as lightness, high strength-to-weight ratio and prefabrication that leads to the possibility to realize lightweight structures having excellent earthquake resistance. Furthermore, timber is a renewable resource, environmentally friendly and aesthetically pleasing when used in new buildings. For all these reasons CLT systems are becoming widespread in Europe and overseas.

The CLT lamination process reduces the scatter of the board properties so that minor strength reducing features such as knots and other defects are dispersed within the product volume [2]-[5]. However, the structural performance of CLT panels depends on the proper application of the glue between the layers. The bond set up at the interface between longitudinal and orthogonal layers can be seriously compromised by the lack of glue occurring during the production process. For this reason, quality control is an essential tool for verifying the correct gluing process of CLT panels. Non-Destructive Testing (NDT) plays an important role in the quality control and integrity assessment of industrial products, because NDT techniques do not compromise the mechanical properties of the product. Among NDT techniques, Ultrasonic Testing (UT), based on measurements 
of the characteristics of acoustic waves propagating through the material, is generally used in quality control of wooden elements. Aicher et al. [6] showed the feasibility of the ultrasound pulse transmission method in order to detect and characterize the presence of longitudinal cracks in Glued Laminated Timber (GLT) beams. Hasenstab and Osterloh [7] used a combination of low frequency ultrasonic echo and X-rays techniques on damaged wooden structural elements and stated that damages can be detected by the use of ultrasound echo from the undamaged side of the specimen, while the extent of the damages can be obtained by mobile X-ray inspection. Moreover, the results showed that ultrasonic methods were the most sensitive in detecting early stages of decay and cracks developed parallel to the surface, while X-rays yielded a direct picture of the position of the knots.

Several researchers applied UT to the gluing quality control of GLT. Sanabria et al. [8], [9] carried out air-coupled ultrasound slanted lateral method in order to assess delamination in GLT elements and demonstrated that the method was suitable to identify lack of adhesive in glued timber objects. Dill-Langer et al. [10] showed the feasibility of detection of glue-line defects of GLT elements by means of ultrasonic methods.

\section{BASICS OF ULTRASONIC TESTING}

UT is based on the study of phenomena connected with the spread of acoustic waves propagating through the material. The acoustic waves are artificially generated by a piezoelectric transducer (emitter) and acquired after passing through the material by means of a similar transducer acting as a receiver [11]. A coupling agent is generally applied to the faces of the transducers in order to reduce signal energy dissipation due to acoustic impedance difference between the materials in contact. Lots of information can be drawn from analysis of the parameters connected with the propagation of the acoustic waves inside the specimens. The information deal with the level of homogeneity, the quality and the presence of deterioration of the materials or elements under test, the identification of possible defects inside of the material, etc. [12], [13].

The following features are connected with the acoustic waves propagation through the material:

- transit time: time taken by the signal to cover the distance from the emitter transducer to the receiver transducer inside the material under examination;

- signal propagation velocity: ratio of the distance between emitter and receiver transducers to the transit time;

- $\quad$ signal attenuation characteristics.

In general, the signal propagation velocity is a less sensitive feature to the conditions of the test (e.g. propagation distance, coupling conditions, transducer type) compared to the signal attenuation characteristics (amplitude or frequency content) [14]-[16], but it is the easiest and quickest feature to measure.

UT is generally carried out applying three different transmission techniques depending on the arrangement of the transducers on the specimen surface as shown in Fig. 1:

1. Direct Transmission Technique (DTT): the wave is transmitted by an emitter through the item and received by a receiver placed on the opposite side.

2. Semi-direct Transmission Technique (STT): the emitter and the receiver transducers are placed on consecutive sides of the item.

3. Indirect Transmission Technique (ITT): both the emitter and the receiver transducers are placed on the same side of the item. 


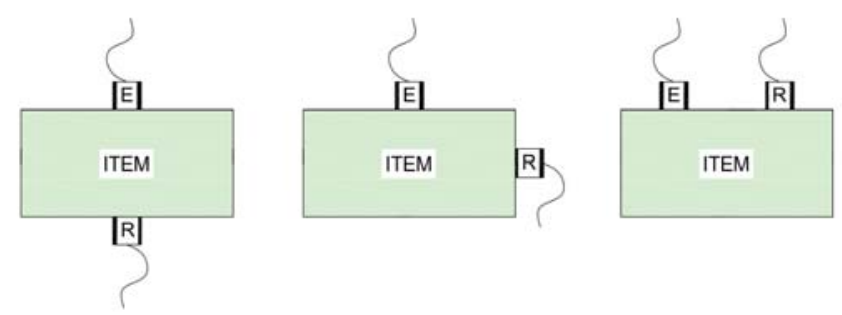

Figure 1: UT. From left to right: Direct, Semi-direct, Indirect Transmission Techniques.

ITT and STT are less effective than DTT due to a great decrease in amplitude of the received signal, and the pulse propagating in the item just beneath the surface. Conversely in DTT the direction of wave propagation is perpendicular to the source surface and the signal travels through the entire thickness of the item [14].

Traditional applications of UT are based on measurements of the velocity of longitudinal stress waves according to the following relationship:

$$
V=\frac{L}{T},
$$

where $\mathrm{V}$ is the velocity of longitudinal stress waves and $\mathrm{T}$ is the time waves need to travel along the path of length $\mathrm{L}$.

From the wave's propagation theory, $\mathrm{V}$ depends upon dynamic elastic modulus $\mathrm{E}_{\mathrm{d}}$, Poisson's ratio $v$ and density $\rho$. For a homogeneous isotropic material, eqn (2) applies:

$$
V=\sqrt{\frac{E_{d}}{\rho} \cdot \frac{(1-v)}{(1+v) \cdot(1-v)}}
$$

Thus, the velocity of longitudinal stress waves is related to the elastic properties and mass of the material, so that if mass and $\mathrm{V}$ are known, the elastic properties can be assessed [14]-[17]. Moreover, the analysis of $\mathrm{V}$ provides crucial information about the inner conditions of the object, since it is empirically acknowledged that the better the physical and mechanical quality of the object, the higher the velocity.

\section{EXPERIMENTAL PROGRAMME}

The efficacy of UT in detecting adhesion anomalies and defects in CLT panels was explored during the experimental programme.

UT was carried out on 15 CLT panels having different length, thickness and number of layers, and different timber species. The specimens were sorted into 4 groups labelled from A to D. Groups A, C and D were composed of 4 CLT panels, while group B consisted of 3 panels (see Table 1). One CLT panel of each group was perfectly manufactured and used as a reference specimen while other panels had some artificial bonding defects included at the interface between the layers of the timber boards.

Ultrasonic measurements were carried out by means of the DTT technique using the ultrasonic test equipment Pundit Lab+, developed by Proceq.

The quantity $\mathrm{V}$ was measured through the panel thickness along three lines of UT measurement points, called measurement lines, each one composed of 11 measurement points spaced $60 \mathrm{~mm}$ apart (Fig. 2). 
Table 1: Description of the CLT groups.

\begin{tabular}{|c|c|c|c|c|c|}
\hline Group & $\begin{array}{c}\text { Length } \\
{[\mathrm{mm}]}\end{array}$ & $\begin{array}{c}\text { Thickness } \\
{[\mathrm{mm}]}\end{array}$ & $\begin{array}{c}\text { Width } \\
{[\mathrm{mm}]}\end{array}$ & $\begin{array}{c}\text { Number of } \\
\text { layer }\end{array}$ & $\begin{array}{c}\text { Timber species } \\
\text { of layers }\end{array}$ \\
\hline A & 1280 & 60 & 240 & 3 & $\mathrm{~S}^{*}$-MP**-S* \\
\hline B & 740 & 60 & 240 & 3 & $\mathrm{~S}^{*}$-MP**-S* \\
\hline C & 1320 & 120 & 240 & 3 & MP** \\
\hline D & 1100 & 100 & 240 & 5 & MP** \\
\hline
\end{tabular}

$* \mathrm{~S}=$ Spruce; $* * \mathrm{MP}=$ Maritime Pine

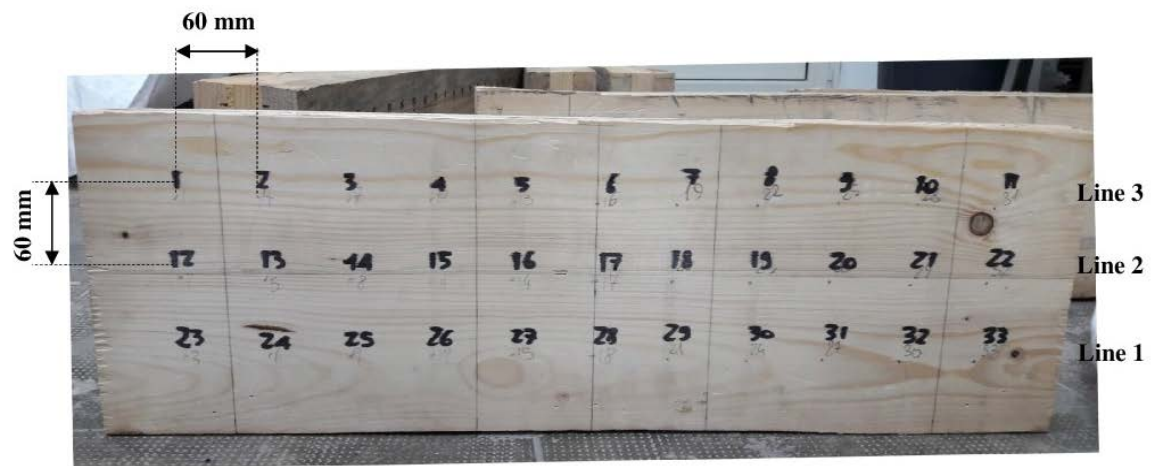

Figure 2: CLT panels surface: UT measurement points and measurement lines.

The testing equipment includes:

- a pair of $54 \mathrm{kHz}$ transducers for emitting and receiving signals;

- a unit for signals generation, acquisition and preliminary analysis;

- a PC for data storage and further signal processing;

- a dedicated software Pundit Link, developed by Proceq, which unlocks the full capabilities of the ultrasonic testing system.

A dry coupling agent was used in order to reduce signal energy dissipation due to acoustic impedance difference between the materials in contact.

\section{DATA PROCESSING}

Table 2 gives a summary of the UT measurements on the CLT panels.

It can be inferred from table 2 that the most scattered property is Vmin, which has a standard deviation about 5 times higher than Vmax and 2 times higher than Vmean. This finding is consistent with the fact that gluing defects cause a sort of delamination of the panel layers determining the formation of voids. These voids slow down the velocity of the waves running through them, whereas highest values of $\mathrm{V}$ are reached in areas without defects regardless of the presence or not of gluing defect in other zones of the panel. Table 2 also points out a negligible effect of the panel configuration (length, thickness and number of the layers, timber species) on the $\mathrm{V}$ values.

\subsection{Analysis of the measurement lines}

In order to provide better evidence of the UT measurements results, for each panel V data of each measurement line were plotted as shown in Figs 3-6. 
It can be noted that all $\mathrm{V}$ data of the reference panels (Figs 3-6 on the left) are very close to the Vmean of the panel. Only few values deviate from the mean, as those measured at point 27 (line 3 ) of the $\mathrm{A} 1$ panel, or points 3 and 6 (line 1) of the $\mathrm{C} 1$ panel. The visual inspection highlighted that these measurements points are affected in their immediate surroundings by the presence of some intrinsic wood defects such as knots and resin pockets (Fig. 7).

Table 2: Summary of the UT measurements.

\begin{tabular}{|c|c|c|c|c|c|c|c|}
\hline Group & Panels & Specimens & $\begin{array}{c}\text { Vmin } \\
{[\mathrm{m} / \mathrm{s}]}\end{array}$ & $\begin{array}{c}\text { Vmax } \\
{[\mathrm{m} / \mathrm{s}]}\end{array}$ & $\begin{array}{c}\text { Vmean } \\
{[\mathrm{m} / \mathrm{s}]}\end{array}$ & $\begin{array}{c}\text { S.D.* } \\
{[\mathrm{m} / \mathrm{s}]}\end{array}$ & $\begin{array}{c}\mathrm{CoV}^{*} \\
{[\%]}\end{array}$ \\
\hline \multirow{4}{*}{ A } & 1 & Reference & 1639 & 2113 & 1865 & 117.77 & 6.31 \\
\cline { 2 - 8 } & 2 & Unglued & 938 & 2239 & 1829 & 229.65 & 12.55 \\
\cline { 2 - 8 } & 3 & Unglued & 642 & 2372 & 1675 & 459.75 & 27.45 \\
\cline { 2 - 8 } & 4 & Unglued & 800 & 1929 & 1567 & 347.09 & 22.14 \\
\hline \multirow{4}{*}{ B } & 1 & Reference & 1824 & 2239 & 2014 & 95.21 & 4.73 \\
\cline { 2 - 8 } & 2 & Unglued & 777 & 2281 & 1719 & 378.86 & 22.04 \\
\cline { 2 - 8 } & 3 & Unglued & 618 & 2076 & 1506 & 435.33 & 28.91 \\
\hline \multirow{4}{*}{ C } & 1 & Reference & 1899 & 2410 & 2096 & 120.95 & 5.77 \\
\cline { 2 - 8 } & 2 & Unglued & 822 & 2419 & 1837 & 457.12 & 24.88 \\
\cline { 2 - 8 } & 3 & Unglued & 631 & 2273 & 1387 & 491.95 & 35.47 \\
\cline { 2 - 8 } & 4 & Unglued & 538 & 2273 & 1632 & 574.65 & 35.22 \\
\hline \multirow{4}{*}{ D } & 1 & Reference & 2056 & 2334 & 2183 & 76.13 & 3.49 \\
\cline { 2 - 8 } & 2 & Unglued & 645 & 2381 & 1937 & 449.28 & 23.19 \\
\cline { 2 - 8 } & 3 & Unglued & 982 & 2364 & 1979 & 324.33 & 16.39 \\
\cline { 2 - 8 } & 4 & Unglued & 1118 & 2410 & 2069 & 240.54 & 11.62 \\
\hline \multicolumn{2}{|c|}{ S.D.* $[\mathrm{m} / \mathrm{s}]$} & 524 & 141 & 234 & & \\
\hline
\end{tabular}

*S.D. $=$ Standard Deviation; $\mathrm{CoV}=$ Coefficient of Variation.
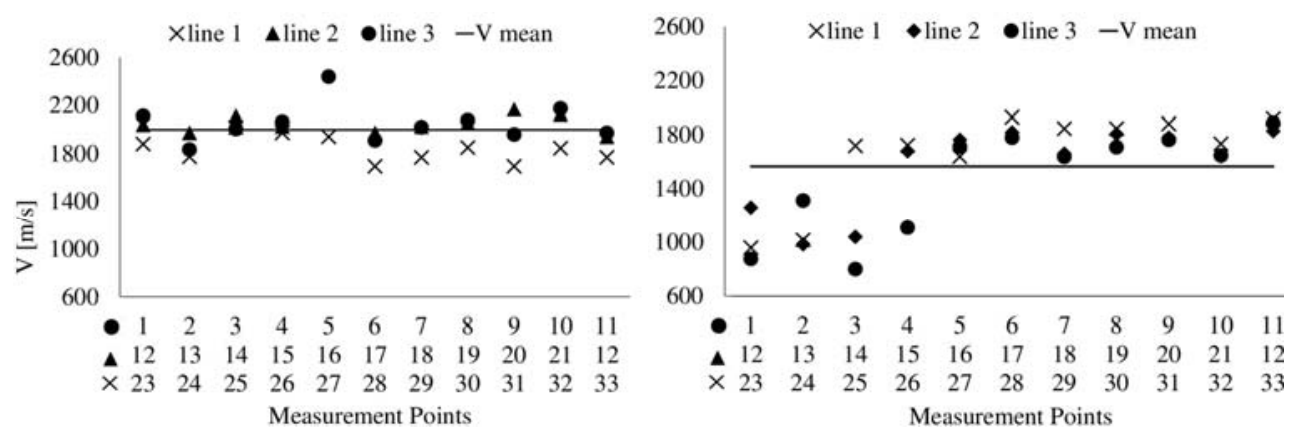

Figure 3: Group A: V distribution along the measurement lines. A1 (left) is the perfectly manufactured reference panel; A4 (right) is a partially unglued panel. 

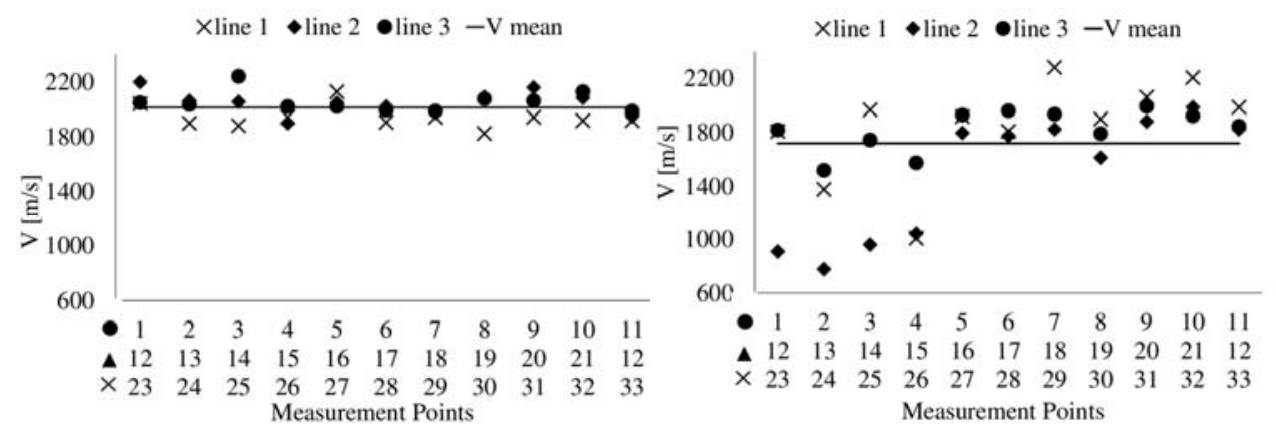

Figure 4: Group B: V distribution along the measurement lines. B1 (left) is the perfectly manufactured reference panel; B2 (right) is a partially unglued panel.
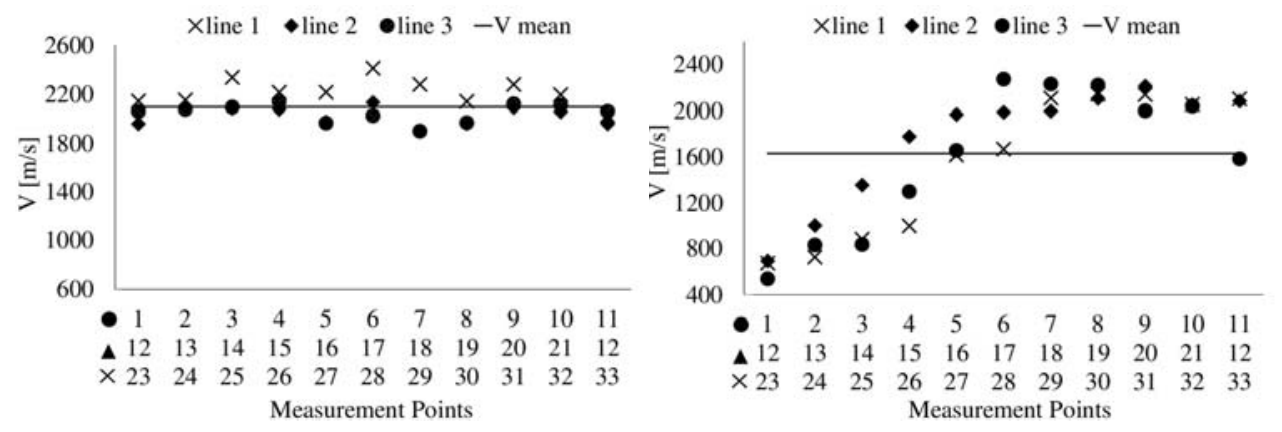

Figure 5: Group C: V distribution along the measurement lines. C1 (left) is the perfectly manufactured reference panel; $\mathrm{C} 4$ (right) is a partially unglued panel.
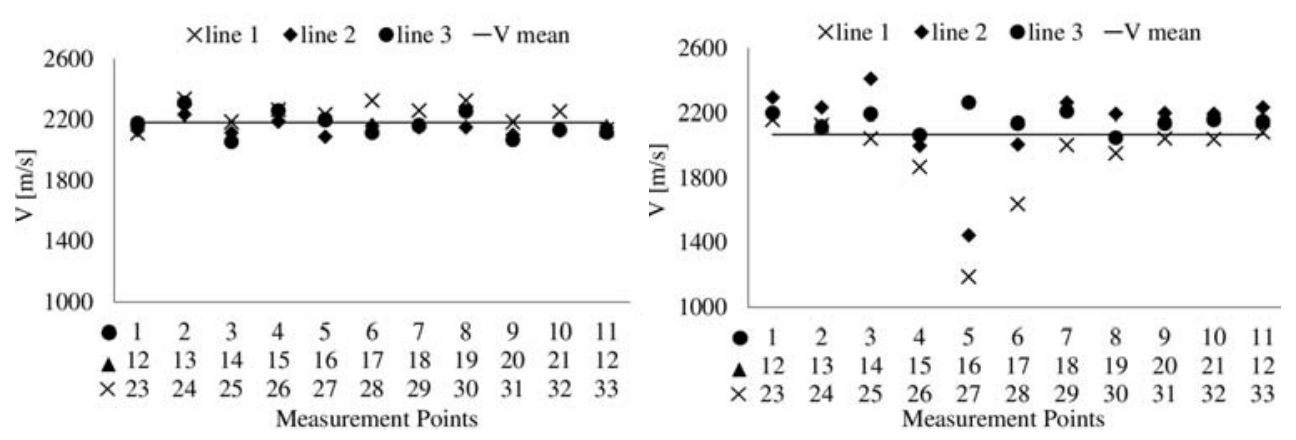

Figure 6: Group D: V distribution along the measurement lines. D1 (left) is the perfectly manufactured reference panel; D4 (right) is a partially unglued panel. 


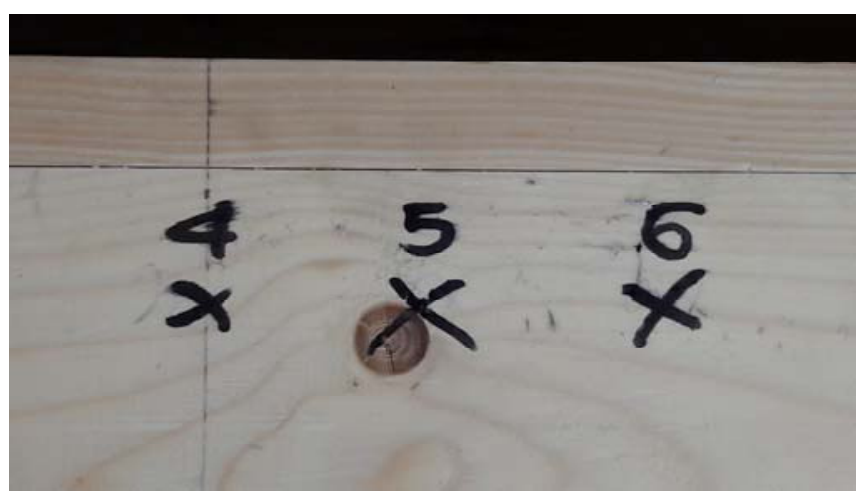

Figure 7: A knot in the immediate surroundings of a measurement point.

These defects are characterized by physical properties, e.g. density, different from those of non-defective wood. Such different properties might influence the velocity of the ultrasonic wave associated to the path starting from or arriving to the point affected by the defect causing $\mathrm{V}$ to deviate from the mean value.

On the contrary, V data of the partially unglued panels (Figs 3-6 on the right) are highly scattered with respect to the Vmean. The values under the Vmean line suggest the presence of some anomalies such as gluing defects and identify defective areas in very good agreement with visual inspection. Furthermore, the comparative analysis of measurement lines plots and visual inspection outcomes (position of knots and resin pockets, location and size of unglued areas) highlighted that the $\mathrm{V}$ values measured on points affected by intrinsic defects of wood (for example point 25, line 3, panel A2 or point 1, line 1, panel C4) are much closer to the Vmean line than values corresponding to unglued areas. This result suggests that unglued areas induce a drop of $\mathrm{V}$ significantly greater than that caused by knots and resin pockets.

\subsection{Kriging method results}

In order to produce a more user-friendly representation of the results, for each panel the distribution of the $\mathrm{V}$ data was graphically represented implementing the iso-velocity curves on a horizontal plane by means of the Kriging method [18], [19]. The Kriging method is an advanced geostatistical procedure where an estimated surface is generated from a scattered set of points. In general, the Kriging method weights the surrounding measured values for deriving a prediction for any unmeasured points. Each data point is weighted by its distance from the neighbouring ones by using the following formula:

$$
Z_{X}=\sum_{i=1}^{n} W_{i} \cdot Z_{i},
$$

where $Z_{X}$ is the predicted value at the point $X, n$ is the number of neighbouring data values used in the prediction, $Z_{i}$ is the value at the point $i$ having a weight $W_{i}$. The weight $W_{i}$, depends on several factors: fitted model to the measured points, distance of the point $i$ to the prediction point and spatial relationships among the measured values around the prediction point. 
As an example, Figs 8-11 show V distributions of some panels belonging to Groups A, $\mathrm{B}, \mathrm{C}$ and $\mathrm{D}$ res pectively. Each figure shows the iso-velocity curves for both perfectly manufactured and partially unglued panels.

As shown in the previous Figs 8-11, the reference panels (Figs 8-11 on the left) exhibit a limited scattering in the distribution of V. On the contrary, the iso-velocity curves

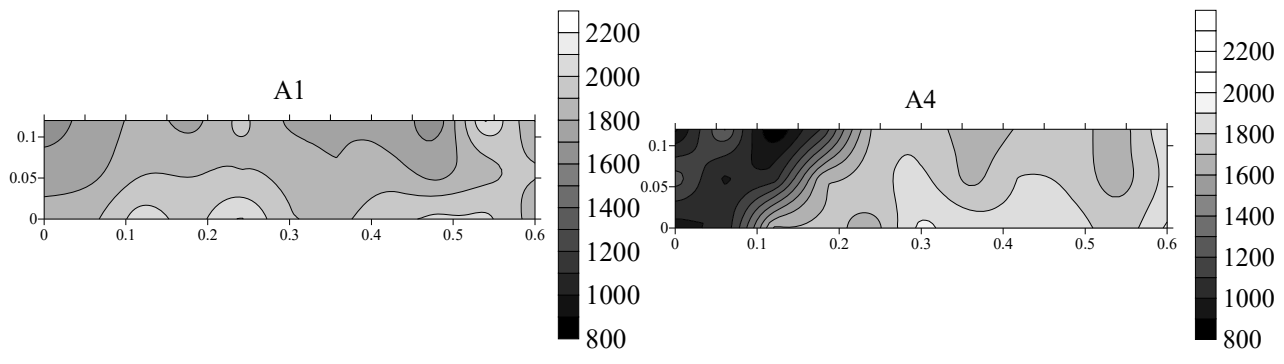

Figure 8: Group A: iso-velocity curves on CLT panels. A1 (left) is the perfectly manufactured reference panel; A4 (right) is a partially unglued panel. V is in $\mathrm{m} / \mathrm{s}$.

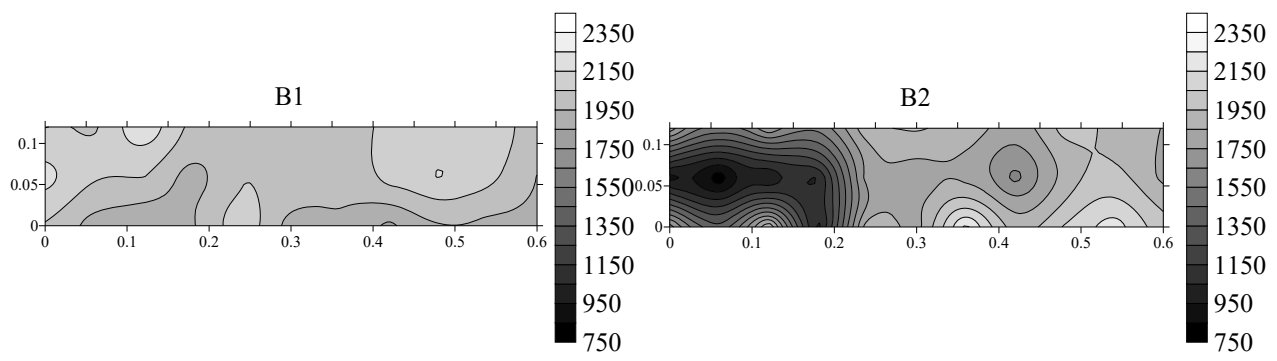

Figure 9: Group B: iso-velocity curves on CLT panels. B1 (left) is the perfectly manufactured reference panel; B2 (right) is a partially unglued panel. V is in $\mathrm{m} / \mathrm{s}$.

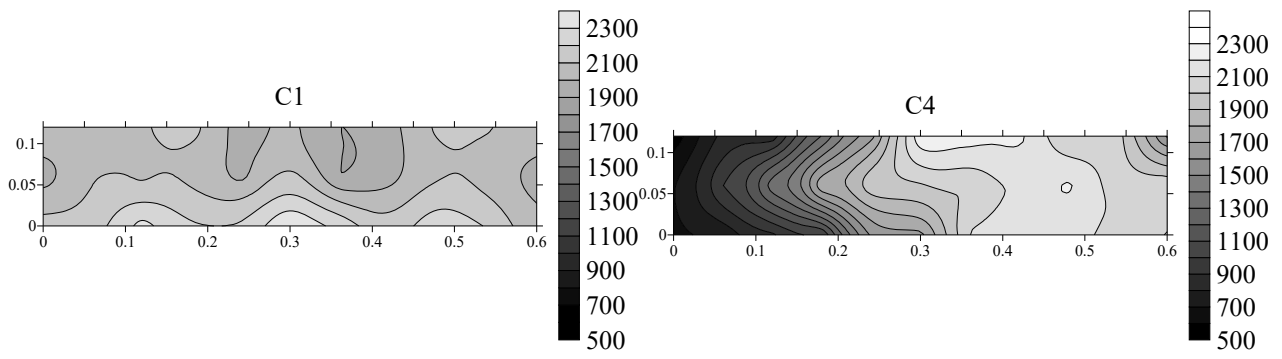

Figure 10: Group C: iso-velocity curves on CLT panels. C1 (left) is the perfectly manufactured reference panel; $\mathrm{C} 4$ (right) is a partially unglued panel. $\mathrm{V}$ is in $\mathrm{m} / \mathrm{s}$. 


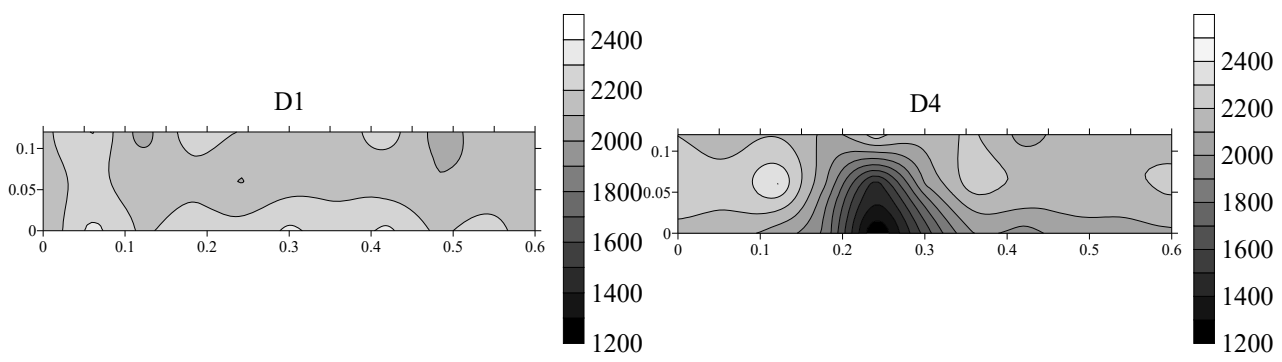

Figure 11: Group D: iso-velocity curves on CLT panels. D1 (left) is the perfectly manufactured reference panel; D4 (right) is a partially unglued panel. V is in $\mathrm{m} / \mathrm{s}$.

of the defective panels (Figs $8-11$ on the right) identify areas where $\mathrm{V}$ decreases from 2 to 3 times. The visual inspection of these panels confirmed that low-V areas match the unglued areas with a good level of accuracy and are in good agreement with the results of measurements lines analysis. It can be noted also that $\mathrm{V}$ distribution of healthy areas is quite similar to that of the reference panels.

The outcomes of the Kriging method provide iso-velocity maps that allow the areas where anomalies are located to be quickly displayed. V maps might therefore provide a powerful tool in the diagnosis of gluing defects in CLT panels. It is, however, worth noting that this representation of the results, albeit very intuitive, is not as accurate as that of the measurement lines. In fact, as previously mentioned the presence of some intrinsic wood defect (knots, resin pockets) in the immediate surroundings of a measurements point might significantly change the velocity of the wave that starts from or arrives to this point. The successive application of the Kriging method, which predicts the values of $\mathrm{V}$ from a weighted interpolation of measured data, would amplify the errors originating from wrong $\mathrm{V}$ values. On the contrary, as explained in section 3.1, the measurements lines analysis shows the punctual $\mathrm{V}$ values allowing the user to distinguish the points affected by intrinsic wood defects from those affected by gluing defects.

\section{CONCLUSIONS}

The paper illustrates the preliminary results of an experimental programme carried out on CLT panels in order to evaluate the effectiveness of UT in detecting gluing anomalies and defects. For this purpose, 15 CLT panels, having different length, number and thickness of the layers and made of different timber species, were tested by means of UT. The specimens were sorted into 4 groups according to the above-mentioned features. Each group included a perfectly manufactured panel, regarded as the reference panel, and other panels on which some artificial gluing defects were introduced at the interface between the lay-up of the timber boards.

The analysis of the ultrasonic velocity values leads to the following outcomes:

- The most scattered property is Vmin, which has a standard deviation significantly higher than Vmax and Vmean. This is consistent with the fact that gluing defects cause the onset of delamination areas between panels layers which slows down the velocity of the waves that run through these areas. Highest values of $\mathrm{V}$ are attained in healthy areas regardless of the presence or not of gluing defect in other zones of the panel. 
- The configuration of the panels (length, thickness and number of the layers, timber species) seems to have a negligible effect on $\mathrm{V}$ values.

- Intrinsic wood defects, such as knots end resin pockets, located in the immediate surroundings of a measurements point affect the velocity of the wave travelling from or to this point, because their physical properties, e.g. density, are different from those of non-defective wood. The effect of these defects on $\mathrm{V}$ distribution might be confused with that of gluing defect causing a wrong data interpretation.

- The analysis of ultrasonic measurements lines highlights that unglued areas induce a drop of V significantly greater than that caused by knots and resin pockets. This analysis also allows the unglued areas to be located within the specimen with a high degree of accuracy.

- The Kriging method leads to the determination of iso-velocity maps, which allow the user to quickly and easily identify defective areas. These maps can be an effective tool for detecting gluing defects, as long as possible errors due to the presence of intrinsic wood defects that may alter the velocity values are carefully taken into account.

\section{ACKNOWLEDGEMENT}

This work was funded and supported by the Operating Program of Regione Sardegna (European Social Fund 2007-2013), L.R.7/2007, 'Promotion of scientific research and technological innovation in Sardinia'.

\section{REFERENCES}

[1] Trulli, N., Valdés, M., De Nicolo, B. \& Fragiacomo, M., 2017. Grading of LowQuality Wood for Use in Structural Elements. Concu, G. (ed). Wood in Civil Engineering, InTech, Online. http://www.intechopen.com/books/wood-in-civil\%20engineering/grading-of-low-quality-wood-for-use-in-structural-elements. DOI: $10.5772 / 67129$.

[2] Schickhofer, G. \& Augustin, M., Final Report Project INTELLIWOOD - Working Package 3 - Strength Correspondence. Lignum Research Graz, Timber Research Association: Graz, Austria, 2001.

[3] Concu, G., De Nicolo, B., Fragiacomo, M., Trulli, N. \& Valdes, M., Grading of Maritime Pine from Sardinia (Italy) for use in cross-laminated timber. Proceedings of the Institution of Civil Engineers - Construction Materials, 2017. DOI: http://dx.doi.org/10.1680/jcoma.16.00043. ISSN 1747-650X; E-ISSN 1747-6518

[4] Smith, R.E., Interlocking cross-laminated timber: alternative use of waste wood in design and construction. Proceedings of the BTES Conference 2011 - Convergence and Confluence, Toronto, ON, Canada. Published by Ghantous, S., Vincent Hui, V. \& Meyer Boake, T. (eds), Building Technology Educators' Society: Toronto, ON, Canada. 2011.

[5] Concu, G., De Nicolo, B., Trulli, N., Valdés, M. \& Fragiacomo, M., Strength class prediction of Sardinia grown timber by means of non-destructive parameters. Advanced Materials Research, 778(3), pp. 191-198, 2013.

[6] Aicher, S., Dill-Langer, G. \& Ringger, T., Non-destructive detection of longitudinal cracks in glulam beams. Otto-Graf-Journal, 13, 2002.

[7] Hasenstab, A. \& Osterloh, K., Defects in wood non-destructive locating with low frequency Ultrasonic Echo Technique. Proceedings of NDTCE'09: Non-Destructive Testing in Civil Engineering, Nantes, France, Online. http://www.ndt.net/article/ndtce2009/papers/214.pdf. 
[8] Sanabria, S.J., Furrer, R., Neuenschwander, J., Niemz, P. \& Sennhauser, U., Novel slanted incidence air-coupled ultrasound method for delamination assessment in individual bonding planes of structural multi-layered glued timber laminates. Ultrasonics, 53(7), pp. 1309-1324, 2013. doi: http://dx.doi.org/10.1016/ j.ultras.2013.03.017.

[9] Sanabria, S.J., Mueller, C., Neuenschwander, J., Niemz, P. \& Sennhauser, U., Aircoupled ultrasound as an accurate and reproducible method for bonding assessment of glued timber. Wood Sci Technol, 45(4), pp. 645-659, 2011. doi: 10.1007/s00226010-0357-z.

[10] Dill-Langer, G., Bernauer, W. \& Aicher, S., 2005. Inspection of Glue-Lines of Glued-Laminated Timber by Means of Ultrasonic Testing. Proceedings of the 14th International Symposium on Nondestructive Testing of Wood, University of Applied Sciences, Shaker Verlag: Germany, Eberswalde, Online. http://www.ndt.net/article/v11n04/dill-langer1/dill-langer1.htm. ISBN 3-8322-39499.

[11] Krautkramer, J. \& Krautkramer, H., Ultrasonic testing of materials, Springer Verlag: New York, 1990.

[12] De Nicolo, B., Piga, C., Popescu, V. \& Concu, G., 2012. Non-Invasive Acoustic Measurements for Faults Detecting in Building Materials and Structures, Zahurul Haq (ed.), Applied Measurement Systems, InTech, Online: http://www.intechopen.com/books/applied-measurement-systems/non-invasiveacoustic-measurements-for-faults-detecting-in-building-materials-and-structures. ISBN: 978-953-51-0103-1,

[13] Aggelis, D.G., Wave propagation through engineering materials; assessment and monitoring of structures through non-destructive techniques. Material and Structures, 46(4), pp. 519-532, 2013. doi:10.1617/s11527-013-0020-x.

[14] Blitz, J. \& Simpson G, (eds), Ultrasonic Methods of Non-Destructive Testing, Chapman \& Hall: London, 1996.

[15] Concu, G., De Nicolo, B., Piga, C. \& Popescu, V., Measurement system for nondestructive testing using ultrasonic tomography spectral attenuation. Proceedings of the $12^{\text {th }}$ International Conference on Power Electronics and Electrical Engineering, Brasov, Romania, 2010. doi: 10.1109/OPTIM.2010.5510507. ISBN 978-1-42447020-4.

[16] Concu, G., De Nicolo, B., Piga, C. \& Popescu, V., Non-destructive testing on a stone masonry using acoustic attenuation tomography imaging. Proceedings of the $12^{\text {th }}$ International Conference on Civil, Structural and Environmental Engineering Computing, Funchal, Madeira, Portugal, 2009. ISBN 978-1-905088-32-4.

[17] Concu, G., De Nicolo, B., Riu, R., Trulli, N., Valdés, M. \& Fragiacomo, M., Sonic testing on cross laminated timber panels. Proceedings of SEMC 2016: The Sixth International Conference on Structural Engineering, Mechanics and Computation Insights and Innovations in Structural Engineering, Mechanics and Computation. Zingoni, A. (ed), CRC Press/Balkema, pp. 1727-1730, 2016.

[18] Deutsch, C.V. \& Journal, A.G., GSLIB Geostatistical Software Library and User's Guide. Oxford University Press: New York, 1992.

[19] Isaaks, E.H. \& Srivastava, R.M., An Introduction to Applied Geostatistics, Oxford University Press: Oxford, 1989. 